\title{
"A Study to Assess the Effectiveness of Self Instructional Module on Knowledge Regarding the Selected Care of Pre-Eclampsia Patient among Nurses in Selected Hospitals Of Vidarbha Region."
}

\author{
Ms. DiptiShukla \\ ${ }^{I}$ M.Sc. Nursingstudent, SRMM College of Nursing,Sawangi (M),Wardha, Maharashtra. \\ (Dept. of Obstetrical \& Gynaecological Nursing)
}

\begin{abstract}
Effectiveness of Self Instructional Module on knowledge regarding the selected care of preeclampsia patient among nurses.

Background: Pre-eclampsia mothers are more dependent on nurses to meet their basic needs than other Antenatal mothers. It is syndrome of hypertension and proteinuria, is a major cause of maternal and perinatal morbidity and mortality. To minimize mortality and morbidity, it is important to identify cases of pre-eclampsia, to provide efficent and effecticve nursing care to them.

Aim: To assess the effectiveness of self instructional module on knowledge regarding preeclampsia among nurses.

Methods: One group pre testpost test design was used for the study. 60(Nurses working in obstetric ward and $O P$, usingnon probability convenient samplingsampling technique were selected for the study. Knowledge of nurses was assessed by using structured questionnaire before distributing self-learning module (SIM) and after 7 days of distributing SIM endpoint data was collected.

Findings: The SIM was useful in improving the knowledge of nursesInpretest $12 \%$ samples has average knowledge and $80 \%$ samples had good knowledge where as in post test 100\% samples had excellent knowledge.

Conclusion and implications for clinical nursing: The self instructional module significantly improved the knowledge of nurses regarding care of preeclampsia patients.

Such modules shall be prepared on various important subjects and made available for nurses working in clinical areas. It will be cost effective method of updating nurses knowledge.
\end{abstract}

Keywords: Nurses knowledge, Self instructional modules, Preeclampsia.

\section{Introduction}

Pre-eclampsia is a condition that occurs during pregnancy that is characterized by high blood pressure and the presence of proteins in your urine.

Pre- eclampsia usually occurs, if at all, after the 20th week of pregnancy. Also known as "toxemia" or inaccurately called "pregnancyrelated hypertensionIn the pre-eclamptic patient there is a risk of repeated miscarriages and hormone and infertility In first time pregnant women. It is specific multi system disorder of unknown aetiology. The disorder affects 5-7 of pregnancies with an incidence of 236 cases per 1000 deliveries Pre-eclampsia is the single identifiable risk factor in still birth and strongly associated with fetal growth retardation, low birth weight, preterm delivery, respiratory distress, it has been shown that $65 \%$ of fetal deaths occur due to non managed pre-eclamptic mothers. The nursing care differs from patient to patient. The health need of patients change according to their health condition. Pre-eclampsia mothers are more dependent on nurses to meet their basic needs than other Antenatal mothers who can independently perform their activities.

\section{Objectives of the study}

1) To assess the existing knowledge regarding selected care of pre-eclampsia among the Nurses.

2) To assess the effectiveness of self-instructional module on selected care of Pre-eclampsia patients.

3) To associate the post-test knowledge score with selected demographic variables.

\section{Methodology}

Research Design: Is a Quasi experimental" one group pre-test, post-test" research design.

Setting: The research setting selected for the study were A.V.B.R. Hospital, Sawangi,Wardha\& B.J.W Government Hospital, Gondia.

Population: Population for the present study comprised of staff nurses working in obstetric department. Sample Size: The total number of 60 nurses was selected 
Sampling Technique:In the present studynon probability convenient sampling was used for selecting the subject.

\section{Criteria for sample selection:}

1.Nurses who were willing to participate. 2 .

2. Who were working in obstetric ward \& OPD.

3.Available at the time of data collection.

Description of Tools:

A structured questioner schedule to assess the knowledge of nurses regarding the selected care of pre-eclampsia.

\section{Description of questioner:}

Section I- Consists of demographic variables of the subject to be participated in the study e.g. Age, Gender, Professional qualification, Working experience etc.

Section II - Consists of 30 questions on knowledge regarding selected care of pre-eclampsia and the following area were covered in the structured questioner .

$>$ Knowledge regarding pre-eclampsia.

$>$ Knowledge regarding medical and surgical management of pre-eclampsia.

$>$ Knowledge regarding dietary management of pre-eclampsia.

$>$ Knowledge regarding possible complications of pre-eclampsia.

$>$ Knowledge regarding nursing care of pre-eclampsia.

\section{Development of Teaching Program me:}

A self-instructional module was developed to enhance the knowledge onimprovement regarding the care of preeclampsia patients.

The following areas were covered in self-instructional module.

- Introduction

- Meaning of pre-eclampsia

- Medical and Surgical management of pre-eclampsia

- Dietary management of pre-eclampsia

- Complications of pre-eclampsia

- $\quad$ Nursing care of pre-eclampsia

\section{Data Collection}

The data gathering process began from 21/02/2011 to 12/03/2011, An informed consent from the entire participant was taken. First of all, the structured questionnaire administered for assessing the knowledge. After collecting the pre-test data, The Self-instructional module administered to the nurses and after seven days the post test conducted.

\section{Finding of the study}

The table no.1 depicts that the distribution of samples according to their age depicts that $16.7 \%$ of the samples were in the age group of 25-30 years and $50.00 \%$ belonged to $31-35$ years of age. $33.3 \%$ of the samples were in the age group of above 35 years. Hence, it is interpreted that most of the samples under study were between the age group of 31-35 years.

Distribution of samples according to their gender shows that the hundred percentages $(100 \%)$ of samples were Female.. Distribution of samples according to their Educational qualification in nursing shows the majority $(83.33 \%)$ of the nurses were diploma holders in nursing and only $16.66 \%$ of the samples were ANM. Distribution of samples according to their years of experience shows that the highest percentage $(80 \%)$ of samples had 8.1-17- years of experience and $20 \%$ of them had 1.1- 8 years of experience.

Table No- 1: Percentage Wise Distribution of Nursee In Selected Hospitals Of Vidarbha Region According To Their Demographic Variables

\begin{tabular}{|l|l|l|}
\hline Demographic Variables & No. of nurses & Percentage (\%) \\
\hline Age(yrs) & 0 & 0.00 \\
\hline $19-24$ & 10 & 16.7 \\
\hline $25-30$ & 30 & 50.0 \\
\hline $31-35$ & 20 & 33.3 \\
\hline Above 35 & 0 & 0.00 \\
\hline Gender & 0 & \multicolumn{2}{|l|}{} \\
\hline Male &
\end{tabular}


"A Study To Assess The Effectiveness Of Self Instructional Module On Knowledge Regarding The..

\begin{tabular}{|l|l|l|}
\hline Female & 60 & 100.00 \\
\hline Professional Qualification & 10 & 16.66 \\
\hline ANM & 50 & 83.33 \\
\hline GNM & 0 & 0.00 \\
\hline B.SC. N. & 0 & 0.00 \\
\hline P.B. B. SC. N & \multicolumn{2}{|l|}{} \\
\hline Working Experience & 0 & 0.00 \\
\hline 6 mth-1 yr & 12 & 20.00 \\
\hline $1.1-8$ yrs & 48 & 80.00 \\
\hline $8.1-17$ yrs & 0 & 0.00 \\
\hline $17.1-25$ yrs &
\end{tabular}

The Table no.2This table deals with the assessment of knowledge regarding selected care of preeclampsia among nurses. The level of knowledge is divided under following headings poor, average, good, and excellent.The result shows in regards to the pretest, $20 \%$ of nurses had averageknowledge, $80 \%$ of nurses had good knowledge regarding selected care of pre-eclampsia. Whereas in post-test, nurses attained $100 \%$ of excellent knowledge, after giving the self-instructional module.

Table 2: Distribution of Nurses according totheir level of knowledge regarding selected care of pre-eclampsia

\begin{tabular}{|l|l|l|}
\hline \multicolumn{2}{|c|}{$\mathrm{N}=60$} & Post Test \\
\hline $\begin{array}{l}\text { Level of knowledge score } \\
(0-25 \%)\end{array}$ & Pre Test & $0(0.00 \%)$ \\
\hline $\begin{array}{l}\text { Average } \\
(26-50 \%)\end{array}$ & $0(0.00 \%)$ & $0(0.00 \%)$ \\
\hline $\begin{array}{l}\text { Good } \\
(51-75 \%)\end{array}$ & $12(20.00 \%)$ & $0(0.00 \%)$ \\
\hline $\begin{array}{l}\text { Excellent } \\
(>75 \%)\end{array}$ & $48(80.00 \%)$ & $60(100.00 \%)$ \\
\hline p-value & $0(0.00 \%)$ & \\
\hline
\end{tabular}

Table no3, it is evident that the obtained pre-test and pot test score the t-value was 39.18 and p-value was 0.000 which is less than $0.05, \mathrm{So}, \mathrm{H} 1$ is accepted. Hence we conclude that SIM was effective.

This table shows the pre-test and post-test knowledge scores of the selected care of preeclampsia. Mean and standard deviations values are compared and paired ' $\mathrm{t}$ ' test is applied at $5 \%$ level of significance. The tabulated ' $t$ ' value for $n-1$, i.e.59 degrees of freedom is 2.00 . The calculated value was 39.18 respectively for knowledge regarding selected care of preeclampsia. The calculated ' $t$ ' values were much higher than the tabulated values at $5 \%$ level of significance which was statistically acceptable level of significance. In addition the calculated 'p' values for all the areas of knowledge regarding selected care of pre-eclampsia were 0.000 which is ideal for any population.

Table 3: Significance of difference between pre testand post test knowledge score in relation to Pre-eclampsia in Nurses in selected hospital of vidharbha region $\mathrm{N}=60$

\begin{tabular}{|l|l|l|l|l|l|l|}
\hline Overall & Maximum score & Mean & $\begin{array}{l}\text { Standard } \\
\text { deviation }\end{array}$ & Mean percentage & t-value & $\mathrm{p}$-value \\
\hline Pre Test & 22 & 17.73 & 2.32 & 59.11 & 39.18 & 0.000 \\
\cline { 1 - 4 } Post Test & 30 & 29.75 & 0.47 & 99.16 & & $\mathrm{~S}, \mathrm{p}<0.05$ \\
\hline
\end{tabular}

Table no.4 it is evident that in the obtained pre test and pot test score the t-value is 29.37 and p-value was 0.000 which was less than 0.05 , so $\mathrm{H} 1$ is accepted. Hence we conclude that SIM was effective.

Table 4: Significance of difference between pre test and post test knowledge score in relation to knowledge regarding Pre-eclampsia in Nurses in selected hospitals of Vidharbha region. N=60

\begin{tabular}{|l|l|l|l|l|l|l|}
\hline Area & Maximum score & Mean & Standard deviation & Mean percentage & t-value & p-value \\
\cline { 1 - 5 } Pre Test & 9 & 4.91 & 1.29 & 49.16 & 29.37 & 0.000 \\
\cline { 1 - 3 } & 10 & 9.95 & 0.21 & 99.50 & & S,p $<0.05$ \\
\hline
\end{tabular}

Table no.5 it is evident that in the obtained pre test and post test score the t-value was 16.01 and p-value was 0.000 which was less than 0.05 , so $\mathrm{H} 1$ is accepted. Hence we conclude that SIM was effective.

Table 5: Significance of difference between pre test and post test knowledge score in relation to knowledge regarding medical and surgical management of Pre-eclampsia in Nurses in selected hospital of Vidharbha region. $\quad \mathrm{N}=60$

\begin{tabular}{|l|l|l|l|l|l|l|}
\hline Area & $\begin{array}{l}\text { Maximum } \\
\text { score }\end{array}$ & Mean & $\begin{array}{l}\text { Standard } \\
\text { deviation }\end{array}$ & Mean percentage & $\begin{array}{l}\mathrm{t}- \\
\text { value }\end{array}$ & $\mathrm{p}$-value \\
\hline Pre Test & 6 & 3.55 & 1.18 & 59.16 & 16.01 & $\begin{array}{l}0.000 \\
\mathrm{~S}, \mathrm{p}<0.05\end{array}$ \\
\hline
\end{tabular}


“A Study To Assess The Effectiveness Of Self Instructional Module On Knowledge Regarding The..

Table no.6 it is evident that the obtained pre test and post test score the t-value was 13.67 and p-value is 0.000 which was less than 0.05 , so $\mathrm{H} 1$ is accepted. Hence we conclude that SIM was effective.

Table 6: Significance of difference between pre testand post test knowledge score in relation to knowledge regarding dietary management of Pre-eclampsia, in Nurses in selected hospitals of Vidharbha region

$. \mathrm{N}=60$

\begin{tabular}{|l|l|l|l|l|l|l|}
\hline Area & Maximum score & Mean & Standard deviation & Mean percentage & t-value & $\mathrm{p}$-value \\
\cline { 1 - 4 } Pre Test & 5 & 3.16 & 1.04 & 63.33 & 13.67 & 0.000 \\
\cline { 1 - 5 } Post Test & 5 & 4.95 & 0.21 & 99.00 & & S,p $<0.05$ \\
\hline
\end{tabular}

Table no7 it is evident that the obtained pre test and pot test score the t-value was 12.82 and p-value is 0.000 which was less than 0.05.Hence we conclude that SIM was effective

Table 7: Significance of difference between pre testand post test knowledge score in relation to knowledge regarding possible complications of Pre-eclampsia, in Nurses in selected hospitals of Vidharbha region.

$\mathrm{N}=60$

\begin{tabular}{|c|c|c|c|c|c|c|}
\hline Area & Maximum score & Mean & Standard deviation & Mean percentage & $\mathrm{t}$-value & $\mathrm{p}$-value \\
\hline Pre Test & 3 & 1.66 & 0.60 & 55.55 & 12.82 & 0.000 \\
\hline Post Test & 3 & 2.90 & 0.30 & 96.66 & & $S, p<0.05$ \\
\hline
\end{tabular}

Table no.8 it is evident that the obtained pre test and pot test score the t-value was 11.02 and p-value is 0.000 which was less than 0.05 . Hence we conclude that SIM was effective.

Table 8: Significance of difference between pre test and post test knowledge score in relation to knowledge regarding nursing care of Pre-eclampsia , in Nurses in selected hospitals of Vidharbha region.

$$
\mathrm{N}=60
$$

\begin{tabular}{|l|l|l|l|l|l|l|}
\hline Area & Maximum score & Mean & Standard deviation & Mean percentage & t-value & $\mathrm{p}$-value \\
\hline Pre Test & 6 & 4.43 & 1.03 & 73.88 & 11.02 & 0.000 \\
& & & & & & $\mathrm{~S}, \mathrm{p}<0.05$ \\
\hline
\end{tabular}

\section{Association of Knowledge Score In Relation To Demographic Variables}

This section deals with the association of post test knowledge scores with selected demographic variables of the study participants. One way ANOVA and unpaired't' test are used for within group comparisons categorically. Variables having more than two categories, one way ANOVA is used and for variables having two categories unpaired ' $\mathrm{t}$ ' test was used

Table no-9 shows that mean value for all age group, in which mean attitude score for 19-24age group was $0.00 \pm 0.00 \mathrm{SD}$, followed by 25-30age group was $29.50 \pm 0.70$; whereas mean attitude score for 31-35 was $29.73 \pm 0.44$,followed by Above 35age group was $29.90 \pm 0.30$ Association of attitude and age group were calculated with F-value, p value was $0 . .08$ which was more than table value .so, there is no association between age and knowledge regarding selected care of pre-eclampsia

Table 9: Significance of difference on knowledge ofPre-eclampsia care in relation to age.

\begin{tabular}{|l|l|l|l|l|}
\hline Age (yrs) & No. of nurses & Mean knowledge score & F-value & -value \\
\cline { 1 - 3 } $19-24$ & 0 & $0.00 \pm 0.00$ & 2.53 & 0.08 \\
\cline { 1 - 3 } $25-30$ & 10 & $29.50 \pm 0.70$ & & NS, p $>0.05$ \\
\cline { 1 - 3 } $31-35$ & 30 & $29.73 \pm 0.44$ & \\
\cline { 1 - 3 } Above 35 & 20 & $29.90 \pm 0.30$ & \\
\hline
\end{tabular}

Table no.10 by applying one way ANOVA was applied to associate knowledge with educational qualification, in which $\mathrm{t}$-value is 1.86 and $\mathrm{p}$-value $=0.06$, which was more than 0.05 , hence non-significant.

Table 10: Significance of difference on knowledge ofPre-eclampsiacare in relation to professional qualification

\begin{tabular}{|l|l|l|l|l|}
\hline Professional Qualification & No. of nurses & Mean knowledge score & t-value & $\mathrm{p}$-value \\
\hline ANM & 10 & $29.50 \pm 0.70$ & 1.86 & 0.06 \\
\hline GNM & 50 & $29.80 \pm 0.40$ & & NS, p $>0.05$ \\
\cline { 1 - 3 } B.SC. N. & 0 & $0.00 \pm 0.00$ & & \\
\hline P.B. B. SC.N & 0 & $0.00 \pm 0.00$ & & \\
\hline
\end{tabular}


“A Study To Assess The Effectiveness Of Self Instructional Module On Knowledge Regarding The..

Table NO 11- depicts by applying one way ANOVA was applied to associate knowledge with experience, in which $t$-value was 1.37 and $\mathrm{p}$-value $=0.17$, which was more than 0.05 , hence non-significant.

Table 11: Significance of difference on knowledge of Pre-eclampsia care in relation to working experience(yrs) $\mathrm{N}=60$

\begin{tabular}{|c|c|c|c|c|}
\hline Working experience & No. of nurses & Mean knowledge score & t-value & p-value \\
\hline 6 mth-1 yr & 0 & $0.00 \pm 0.00$ & \multirow[t]{4}{*}{1.37} & \multirow{4}{*}{$\begin{array}{l}0.17 \\
N S, p>0.05\end{array}$} \\
\hline $1.1-8 \mathrm{yrs}$ & 12 & $29.58 \pm 0.66$ & & \\
\hline $8.1-17 \mathrm{yrs}$ & 48 & $29.79 \pm 0.41$ & & \\
\hline $17.1-25 \mathrm{yrs}$ & 0 & $0.00 \pm 0.00$ & & \\
\hline
\end{tabular}

The findings show that in pre test scores,48(80\%) of subjects were having good knowledge ,12(20\%)of subjects having average knowledge, but in post-test marks obtained by all the $60(100 \%) \%$ of were excellent in knowledge .There was no significant association between age, gender, professional qualification \& working experience in relation with nurses.

\section{Conclusion}

In my study, the maximum number of subjects according to age $30(50 \%)$ belonged to age group 31 - 35 years, minimum number 10 (16.17) belonged to age 25- 30 years and 20(33.3\%) belonged to above $>35$ years of age, In relation to gender, $100 \%$ subject were female, related to educational qualification, out of 60 subjects maximum 50(83.33) were GNMs and remaining 10(16.66) to ANMs, and related to working experience it revealed that maximum number $48(80.00 \%)$ had $8.1-17$ years of experience. and minimum number 12 $(20.00 \%)$ were having 1.1-8 years of experience.

\section{Discussion}

The findings of the present study shows that nurses are having less knowledge regarding.care of preeclampsia\& its management. Thus the findings are supported by Melzer K, Schutz Y,DrakshayanideviMelzer

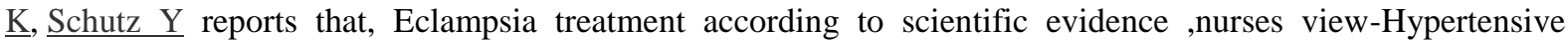
disorders in pregnancy deserve special attention in the setting of global public health. Currently, they represent the third cause of maternal mortality in the world and first in Brazil. From a practical standpoint, pre-eclampsia remains a syndrome that leads to serious repercussions on maternal and fetal mortality and its etiology is not well known.

\section{References}

[1]. Thangaratinam S, Coomarasamy A. Tests for predicting complications of pre-eclampsia. The journal of the Royal Socityofhealth . march 2003; vol.120:13

[2]. Diane M Fraser Margerat A Cooper ; Myles Textbook for Midwives .14 ${ }^{\text {th }}$ edition, published by Churchill Livingstone;2008:page 398-755

[3]. LynnaY.Littleton; Maternity Nursing Care.British Library. $3^{\text {rd }}$ edition ;2001:350-36

[4]. SabaratnamArukumaram; Essentials of obstetrics.Japee Brothers;2006:62-19 